\title{
Research Paper \\ Factor Structure of Personality Inventory for DSM-5 (PID-5) in an Iranian Sample
}

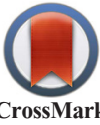

\section{Shiva Soraya ${ }^{1}$, Leila Kamalzadeh ${ }^{1}$, Vahideh Nayeri ${ }^{1}$, Esmat Bayat ${ }^{2}$, Kaveh Alavi ${ }^{3},{ }^{*}$ Seyed Vahid Shariat ${ }^{4}$}

1. Psychiatrist, Mental Health Research Center, Iran University of Medical Sciences, Tehran, Iran.

2. MSc., Department of General Psychology, Mental Health Research Center, Iran University of Medical Sciences, Tehran, Iran.

3. Psychiatrist, Assistant Professor, Mental Health Research Center, School of Behavioral Sciences and Mental Health (Tehran Institute of Psychiatry), Iran University of Medical Sciences, Tehran, Iran.

4. Psychiatrist, Associate Professor, Mental Health Research Center, School of Behavioral Sciences and Mental Health (Tehran Institute of Psychiatry), Iran University of Medical Sciences, Tehran, Iran.

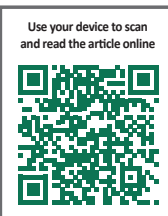

Citration: Soraya Sh, Kamalzadeh L, Nayeri V, Bayat E, Alavi K, Shariat SV. [Factor Structure of Personality Inventory for DSM-5 (PID-5) in an Iranian Sample (Persian)]. Iranian Journal of Psychiatry \& Clinical Psychology. 2017; 22(4):308-317. https://doi.org/10.18869/nirp.ijpcp.22.4.308

doif: https://doi.org/10.18869/nirp.ijpcp.22.4.308

Received: 31 Mar. 2016

Accepted: 14 Sep. 2016

Key words:

Personality disor-

der, validity, Factor

analysis, Inventory

\section{A B STRACT}

Objectives The study was performed to determine the factor structure of the Persian translation of Personality Inventory for DSM-5 (PID 5).

Methods After translation and back translation of PID-5, it was performed on 217 subjects, including 114 healthy students and 103 patients with personality disorders. Exploratory factor analysis was done using principal component analysis and direct oblimin rotation to determine the main factors of the inventory and factor loading of the facets. We used SPSS 20 for data analyses.

Results Using direct oblimin rotation, 5 factors were extracted. The $1^{\text {st }}$ factor Depression-Anxiety includes 8 facets: anhedonia, anxiousness, depressivity, distractibility, emotional lability, impulsiveness, separation insecurity and submissiveness. The $2^{\text {nd }}$ factor Antagonism includes 6 facets: attention seeking, callousness, deceitfulness, grandiosity, hostility and manipulativeness. The $3^{\text {rd }}$ factor Detachment includes 4 facets: intimacy avoidance, restricted affectivity, withdrawal and suspiciousness. The $4^{\text {th }}$ factor includes 5 facets: preservation, rigid perfectionism, impulsiveness, irresponsibility and risk taking. Finally, eccentricity, perceptual dysregulation, unusual beliefs, and experiences were categorized under the 5 th factor Conclusions The Persian version of PID- 5 has acceptable construct validity and could be used as an assessment tool for personality disorders in Iranian samples, if other types of validity and reliability of the tool are proved to be satisfactory.

\section{* Corresponding Author:}

Seyed Vahid Shariat, MD

Address: Mental Health Research Center, School of Behavioral Sciences and Mental Health (Tehran Institute of Psychiatry), Iran University of Medical Sciences, Tehran, Iran.

Tel: +98 (21) 66506862

E-mail: vahid.shariat@gmail.com 


\section{ساختار عاملى يرسش نامه شخصيتى PID-5) DSM-5) در نمونه ايرانى}

شيوا ثريا'، ليلا كمالزاده'، وحيده نيرى'، عصمت بيات؟، كاوه علوى" "سيدوحيد شريعت

ا- ا-روانيزئش، دانشكاه علوم يزشكى ايران، تهران، ايران.

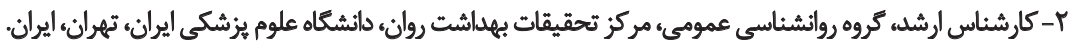

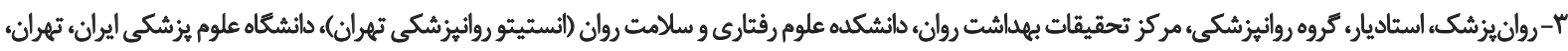

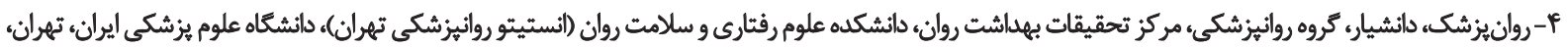

\section{حكبد}

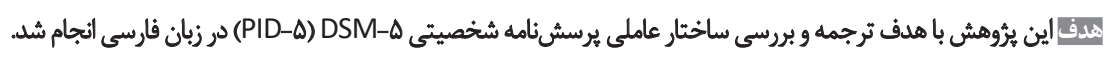

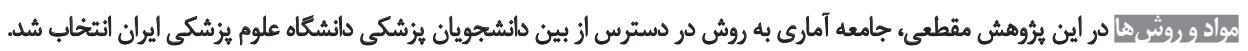

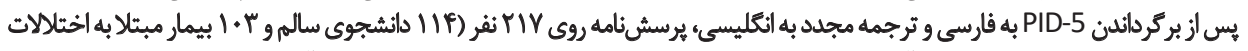

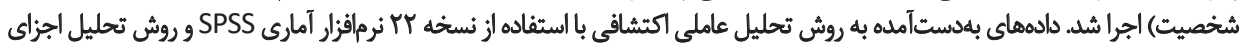

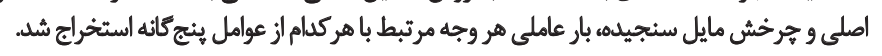

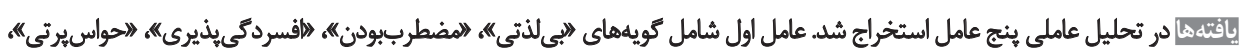

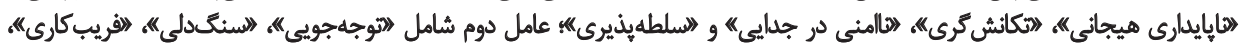

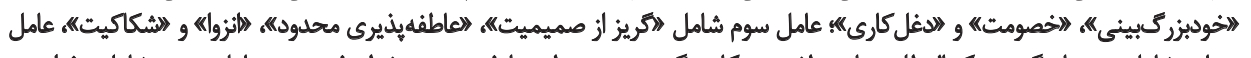

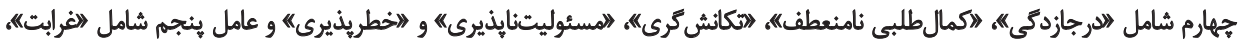

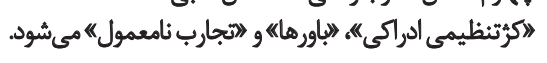

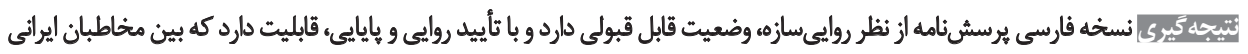
فارسيخبان به عنوان ابززارى براى بررسى اختلالات شخصيتى، كاربرى بالينى داشته باشد.

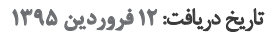

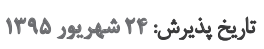

كليدوازهها:

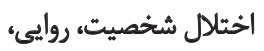
تحليل عاملى، يرسشنامه

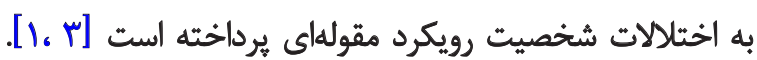

dales

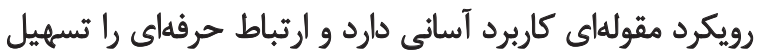

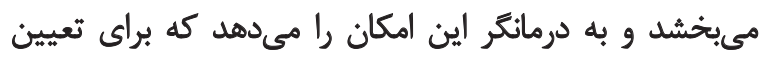

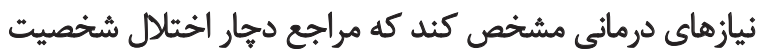

ين رويكرد اطلاعات مفيدى را درباره حالات شديد يا نمونه

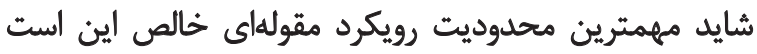
هست يانه [1]

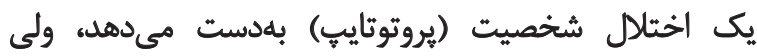

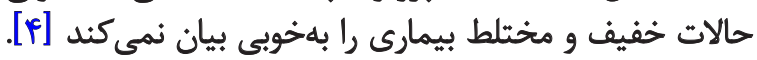

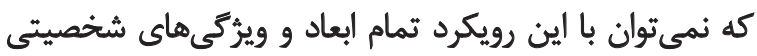

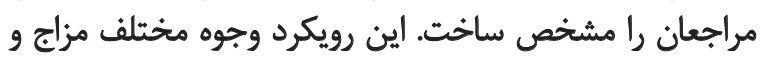

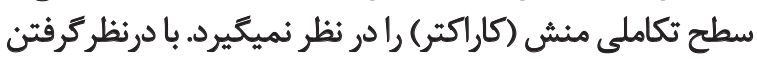

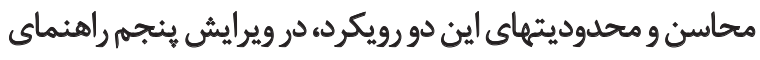

شخصيت شامل الكوهاى بايدار ادراك و تفكر درباره محيط

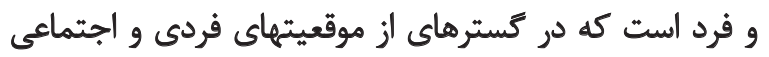

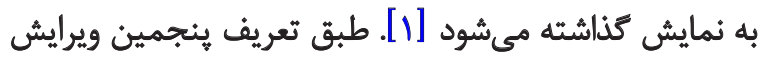

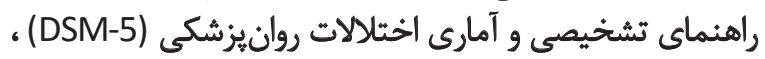

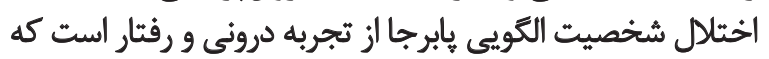

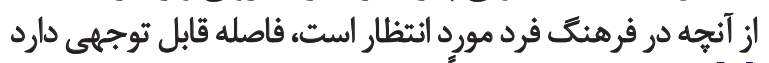

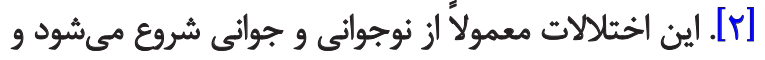

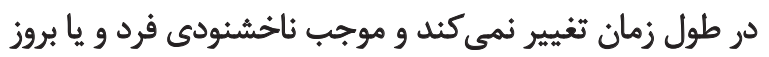

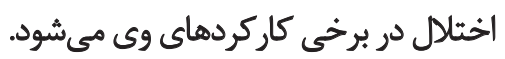

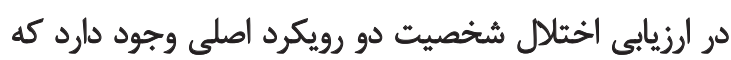

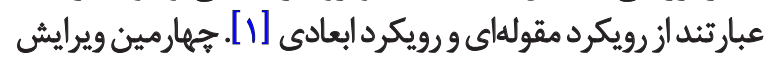
راهنماي تشخيصى و آمارى اختلالات روانيزشكى (DSM-IV-TR)

: نو نويسئده مسئول:

دكتر سيد وحيد شريعت مئد

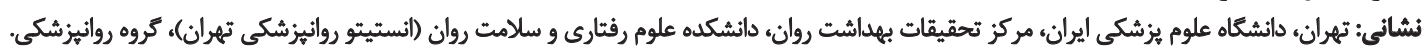
تلفن:

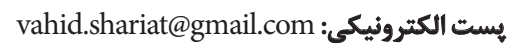




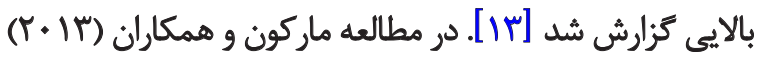

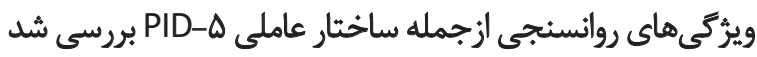

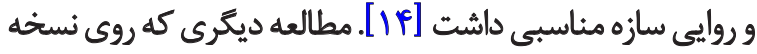

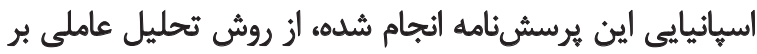

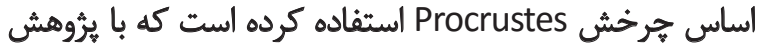

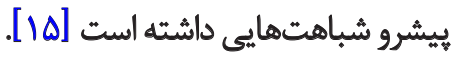

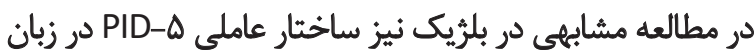

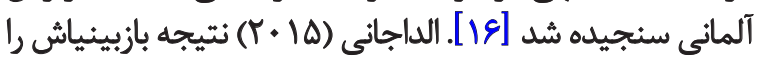

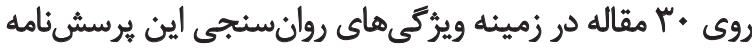

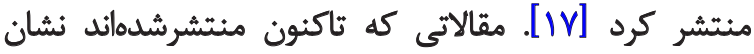

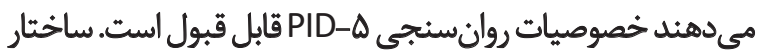

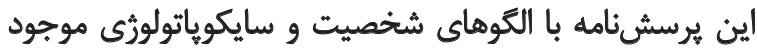

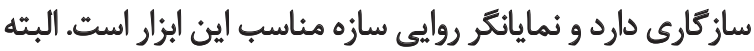

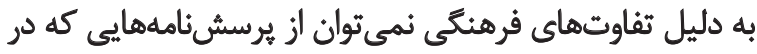

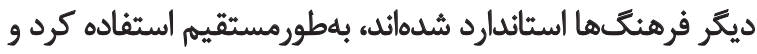

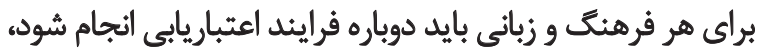

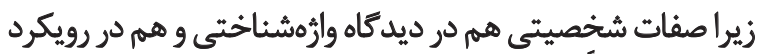

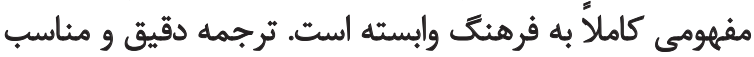

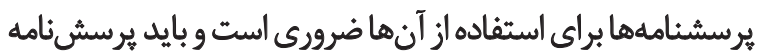

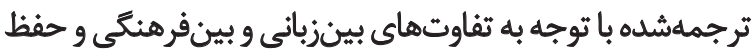

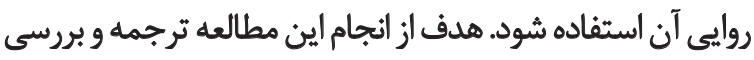

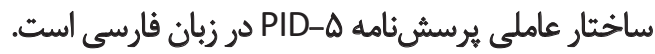

\section{ورث}

اين بثروهش مطالعهاى مقطعى است كه ساختار عاملى فرم

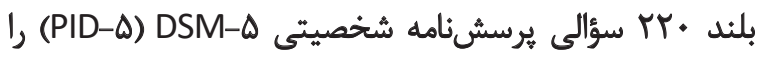

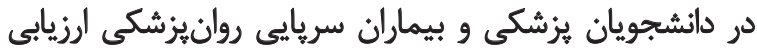

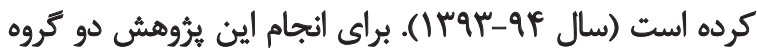

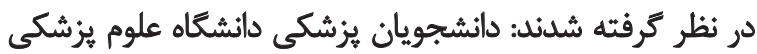

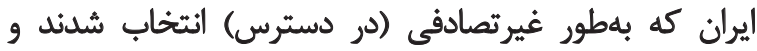

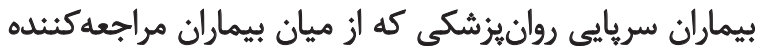

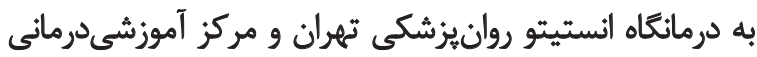

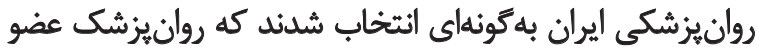

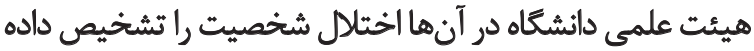

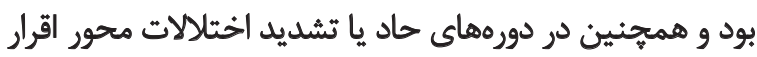
ن أشتند و سايكوتيك نيز نبودند.

معيارهاى ورود به مطالعه در داتشجويان يزشكى شامل رضايت

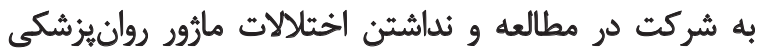

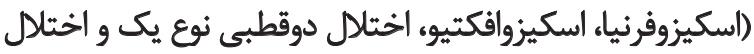

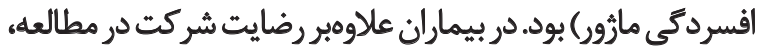

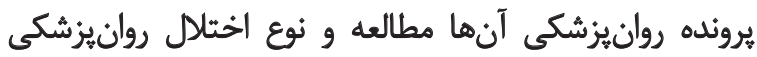

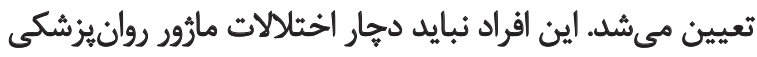
(اسكيزوفرنيا، اختلال اسكيزوافكتيو، اختلال دوقطبى نوع يك إنتات

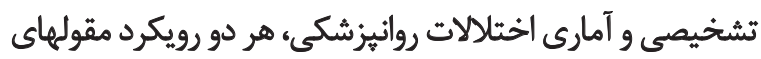

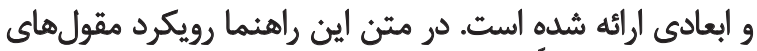

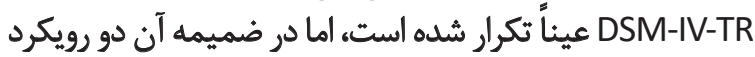

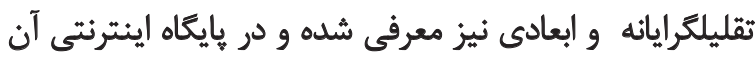

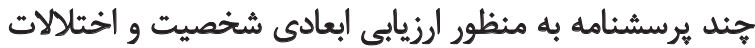

$$
\text { آن معرفى شده است. }
$$

ازجمله يرسش نامه هايي كه بارويكردابعادى تدوين شُهداندمي توان

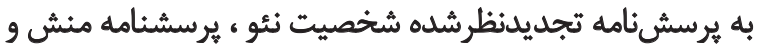

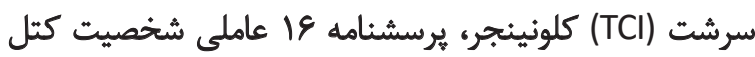

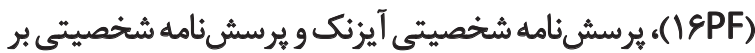

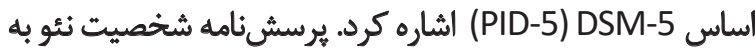

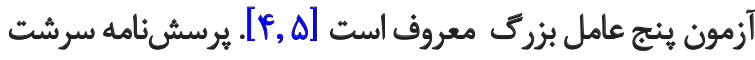

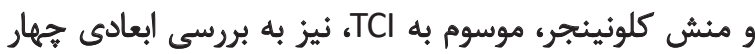

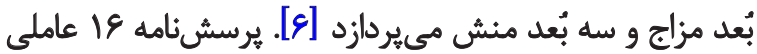

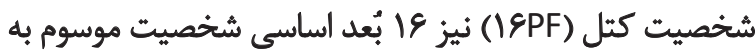

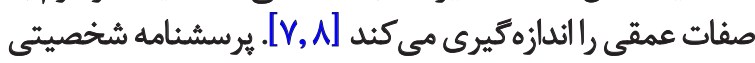

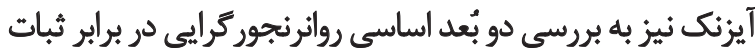

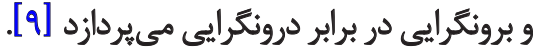

ابزارهاى طراحىشده ابعادى مانند مدل ينج عامل بزرى

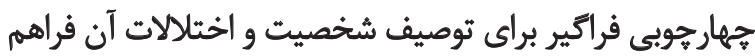

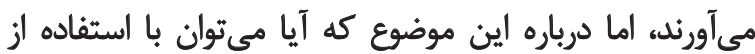

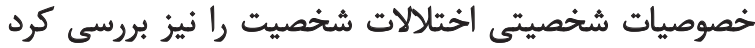

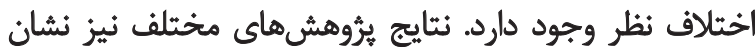

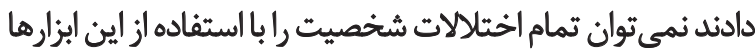

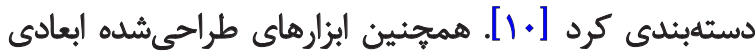

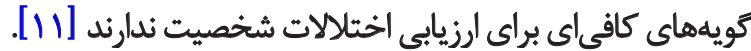

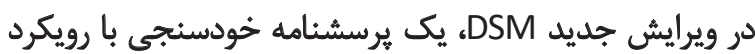

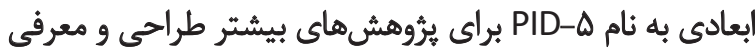

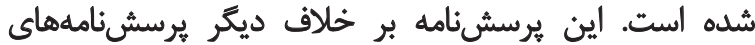

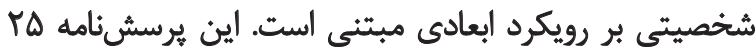

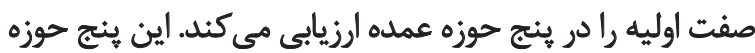

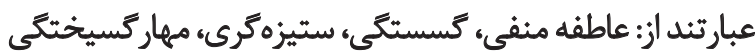

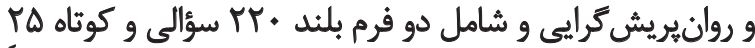

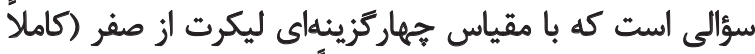

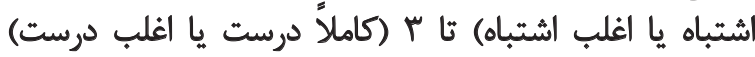

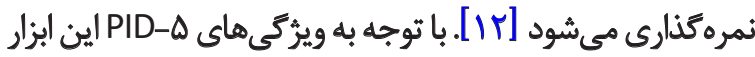

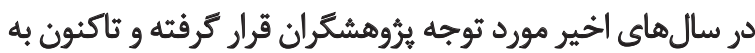
جندين زبان ترجمه و روايى و وايايیى آن ارزيابى شده است

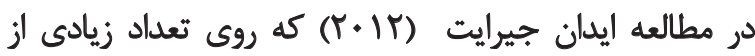

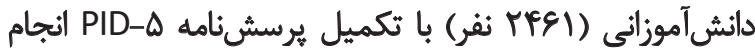

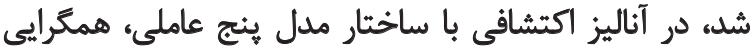


ملاحظات اخلاقي اين مطالعه نيز عبارتند از اينكه در اين مطالعه إنها

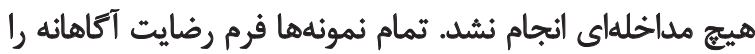

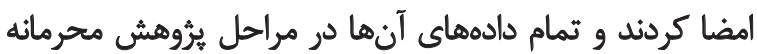

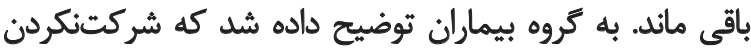

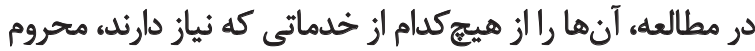

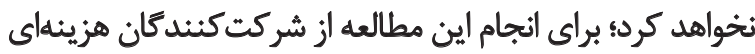

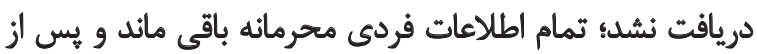

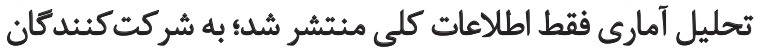

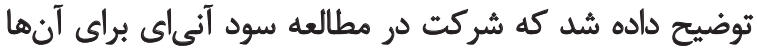

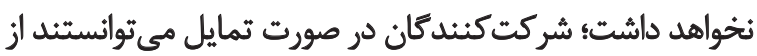
نتايج آزمون خود مطلع شوند؛ و از شركت كتيند

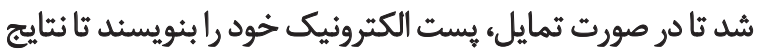
مطالعه يّ از تحليل آمارى به اطلاع آنها بر برسد.

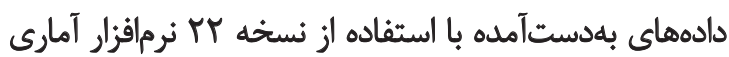

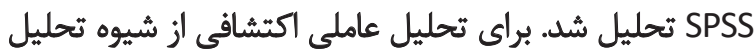

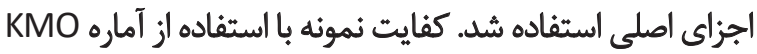

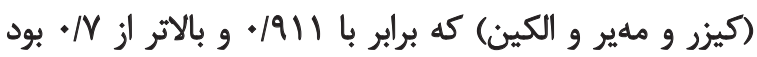

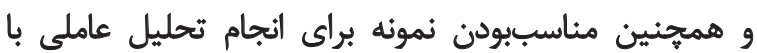
معناداربودن آزمون كرويت بارتلت تأييد شد.

براي تعيين تعداد عوامل از ارزش ويرٔه بالاتر از يك (معيار

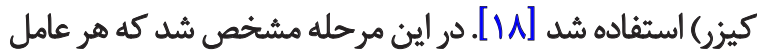

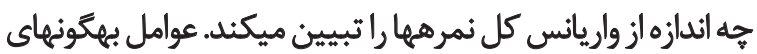

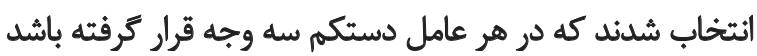

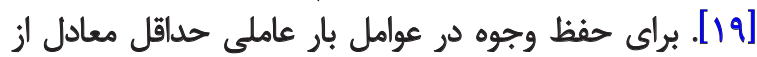

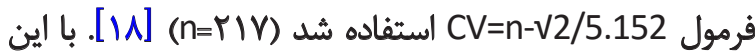

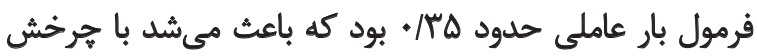

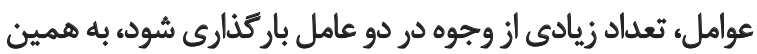

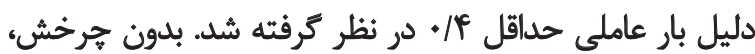

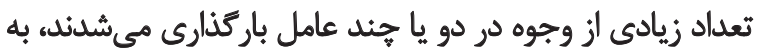

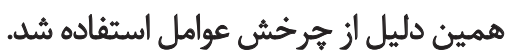

عوامل استخراجشده بدون جرخش با هم همبستخى قابل

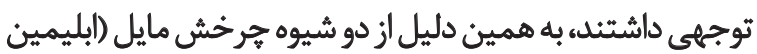

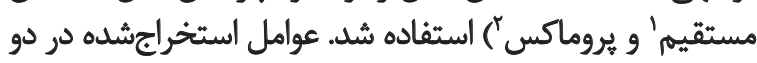

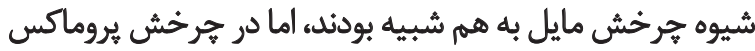

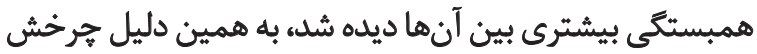

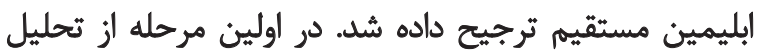

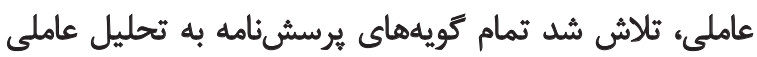

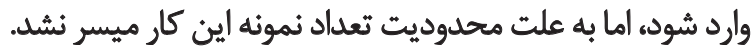

تعداد عوامل استخراجشده حدود •ه له عامل بود و بيشتر اين

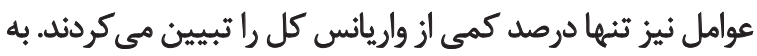

1. Direct oblimin

2. Promax
و اختلال افسردگى ماثور) بودند. وجود علاثم سايكوتيك با بإئا

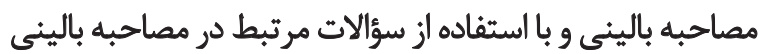

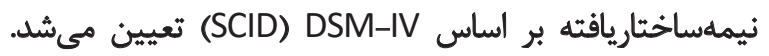
داشتن حداقل تحصيلات سوم راهنمايى و سن 19 تا تا م سال نيز ازجمله ملاكهاى ورود به مطالعه بود.

براى ترجمه برسشنامه، ابتدا يك روانيزشك و سه دستيار

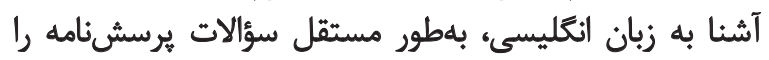

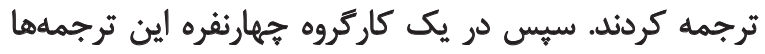

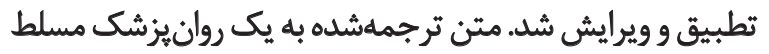

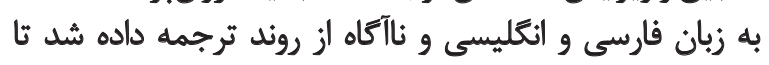

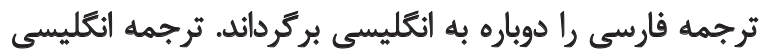

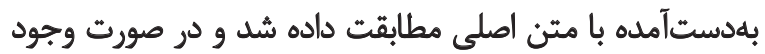

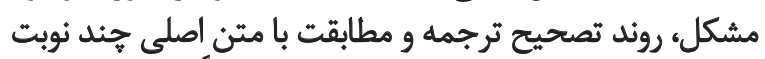

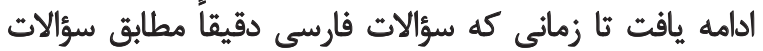
انكليسي ترجمه شافند.

ترجمه نهايى به شش روان بيزشك عضو هيئت علمى دانشعاه

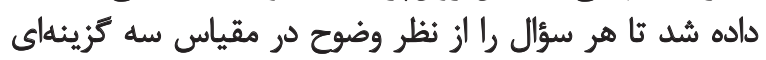

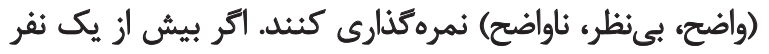

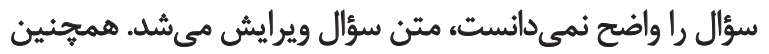

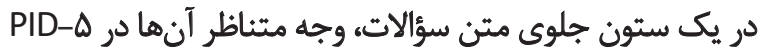

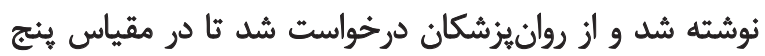

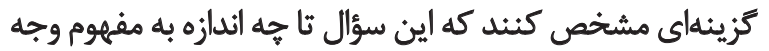

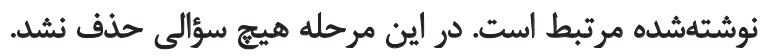

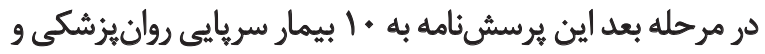

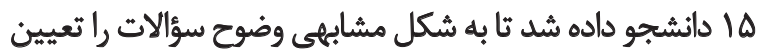

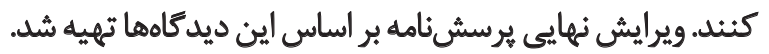

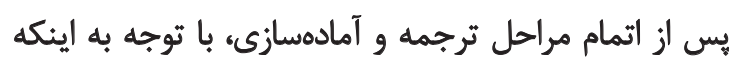

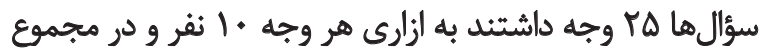

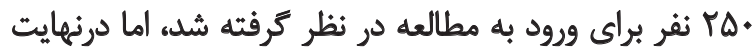

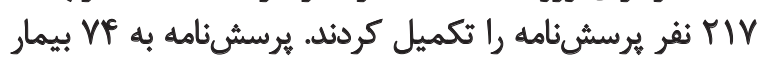

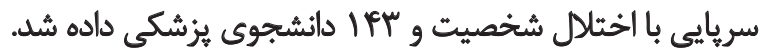

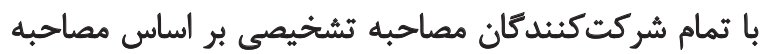

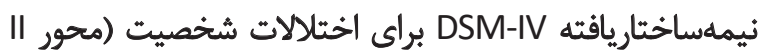

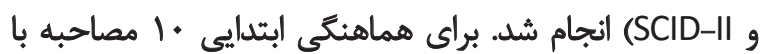

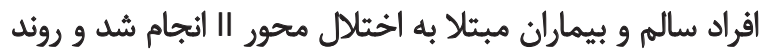

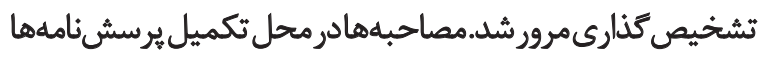

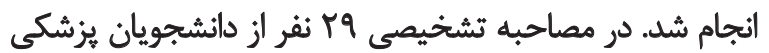

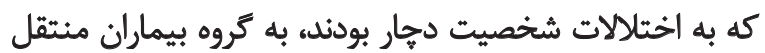

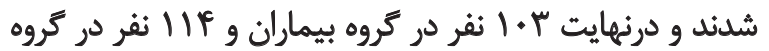

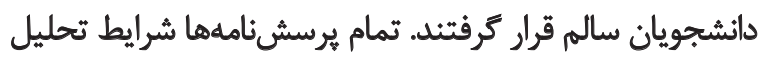

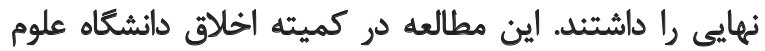
يزشكى ايران تأييد شد. 


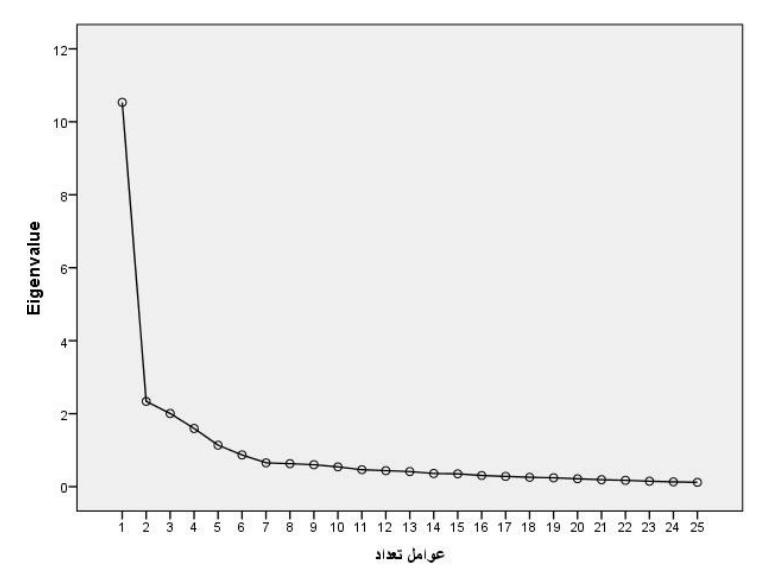

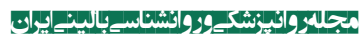

تصوير ا. عوامل استخراج شدهر تحليل عاملى اكتشافى يُرسشنامه ScreeplotPID.

استخراج شد (جدول شماره سٓ). در عامل ئجم با وجود تبيين

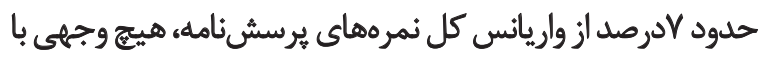

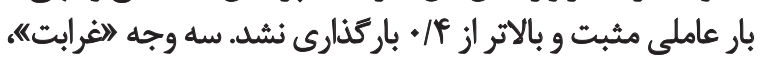

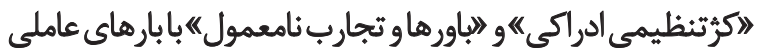

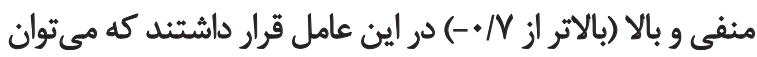

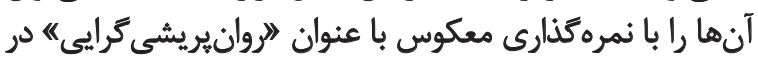

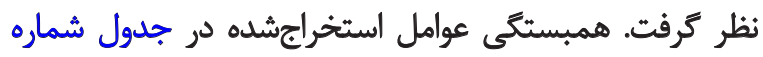

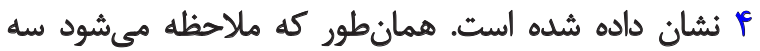

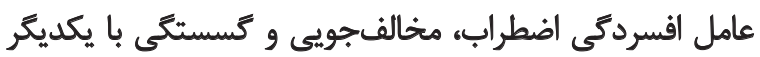

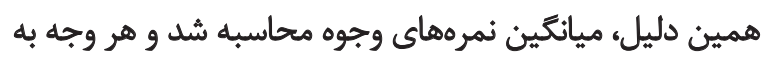

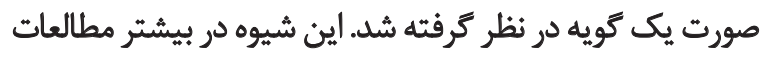

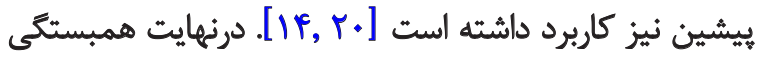

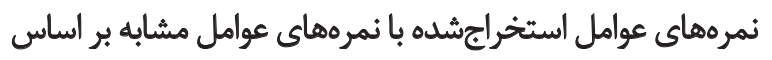

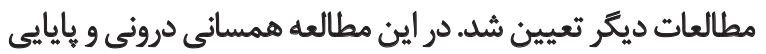

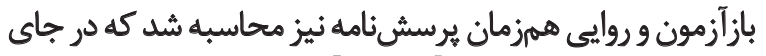

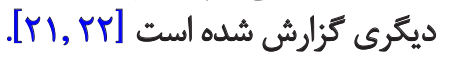

\section{ياثتهها}

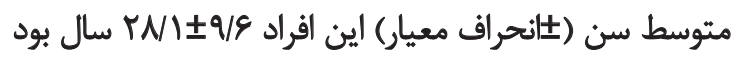

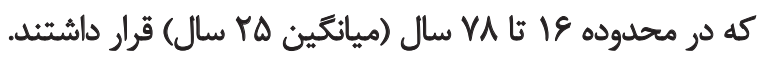

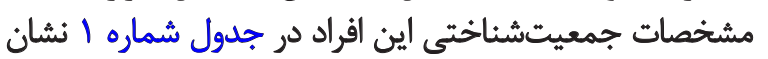

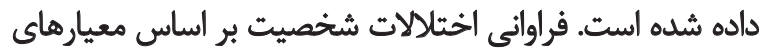

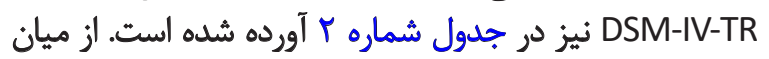

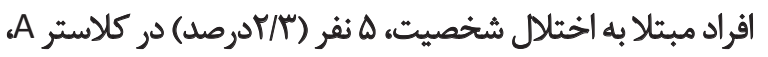
كالأنر ff

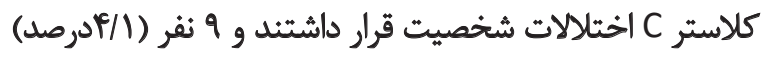

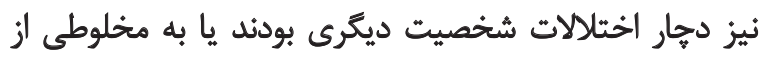

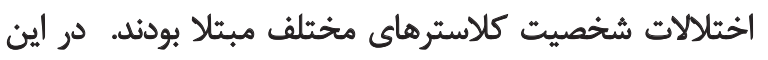
يرسش نامه با درنظركرفتن ارزش ويره بالاتر از يك (معيار كيزر)،

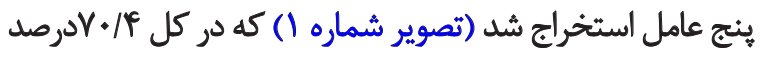

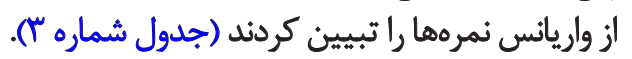
به كمك روش جرخش مايل ابليمين مستقيم، ينج عامل

جدول ا. خصوصيات جمعيتشناختى اثراد مورد بررسى (nIV).

\begin{tabular}{|c|c|c|c|}
\hline درصد فراوانى & فراوانى & طبقات & خصوصيت \\
\hline$M M / S$ & $r$ & مرد مرد & \multirow{3}{*}{ جنسيت } \\
\hline & & & \\
\hline$g \& / f$ & Iff & ij & \\
\hline $8 / 0$ & if & زيردييلم & \multirow{6}{*}{ سطح تحصيلات } \\
\hline $1 \% / \lambda$ & $r$ & دييلم & \\
\hline NA & 19 & فوق دييلم و ليسانس & \\
\hline$m$ & 9 & فوق ليسانس و دكترا & \\
\hline $8 \Delta / 9$ & Ift & دانشجوى يز شكى & \\
\hline .19 & r & نامشَخص & \\
\hline $8 \cdot 1{ }^{2}$ & $\mid m$ & مجرد & \multirow{4}{*}{ وضعيت تأهل } \\
\hline $\mathrm{ru} / \mathrm{A}$ & eq & مهثأهل & \\
\hline $1 / 4$ & $p$ & جليأشده & \\
\hline s/. & ir & نامشخص & \\
\hline
\end{tabular}




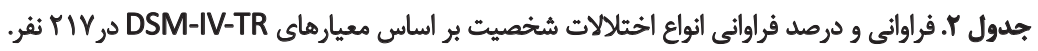

\begin{tabular}{|c|c|c|c|}
\hline درود در بين الخثلالات شخحيث & درصد در كل افراد & 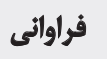 & اخيتلال شُخصيت \\
\hline$r / q$ & $1 / f$ & $r$ & بارانوئيد \\
\hline$r / q$ & $1 / T^{e}$ & $r$ & اسكيزوثيد \\
\hline Na & $r / M$ & $\Delta$ & اسكيزوتاييال \\
\hline rols & $I f / N$ & $M$ & مرزى \\
\hline av & p/g & 1. & خُوششيفته \\
\hline $8 / 1$ & $r / r$ & 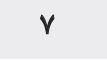 & 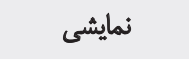 \\
\hline$r / q$ & $1 / 1$ & $f$ & ضد اجتماعى \\
\hline$F I N$ & $19 / 1$ & $R$ & وسواسى-جبرى \\
\hline$I M / 8$ & 81. & ir & 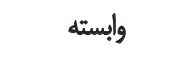 \\
\hline NV & $4 / 1$ & 9 & اجتنابى \\
\hline $1 / 9$ &.$/ 9$ & r & 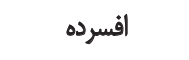 \\
\hline $\mathrm{V} \cdot$ & .10 & 1 & منفعل -ميرخاشكر \\
\hline $\mathrm{V}$ & .10 & 1 & خودشكن \\
\hline $1.0 \%$ & $P V / \Delta$ & $* 1+r$ & جمع \\
\hline
\end{tabular}

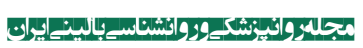

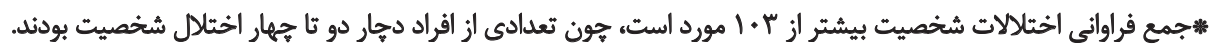

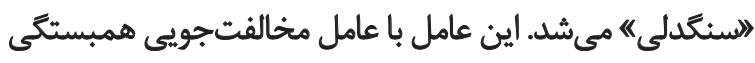

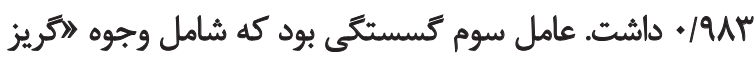

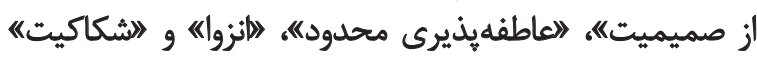

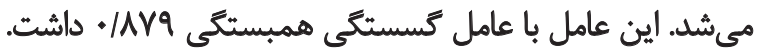
عامل تجهارم مهاركسيختكى بود كه شامل وجوه لاتكانش گرىى"

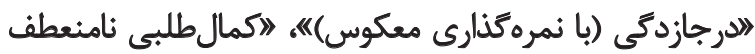

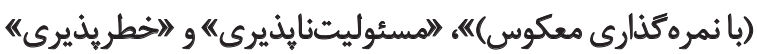

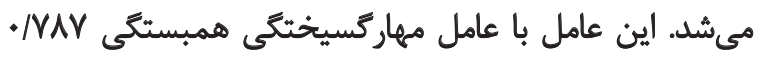

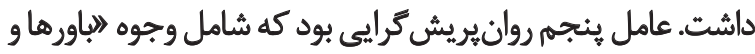

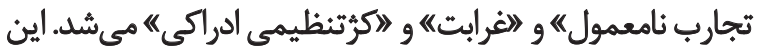

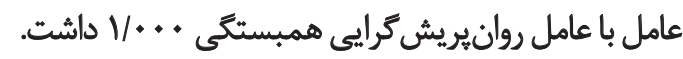

اولين عامل استخراجشده در بررسى حاضر، مفهوم كلى

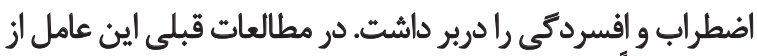

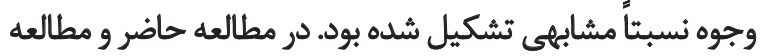

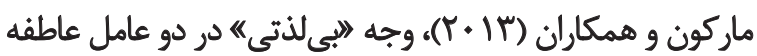

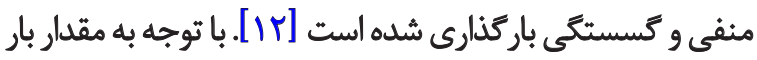
عاملي كه در اين مطالعه در عامل اول بالاتر بود و مفهوم اساسي

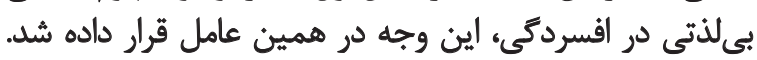

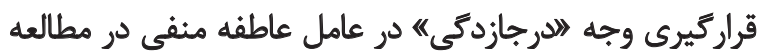

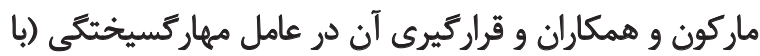

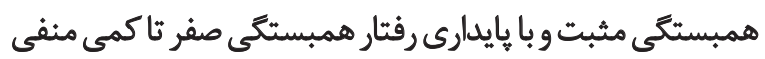

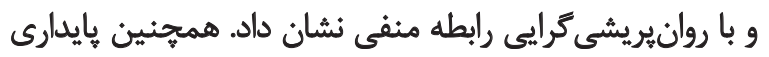

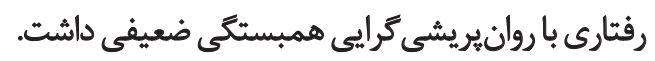
ثب

اين يثروهش با هدف ترجمه و بررسى ساختار عاملى يرسش نامس

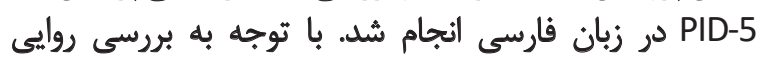

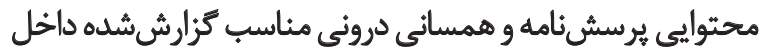
هر وجه، مي توان تصور كرد هر كويه شامل تعدادى كويه همر استا

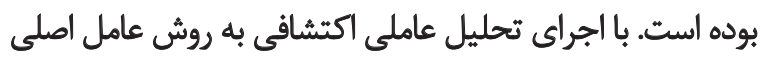

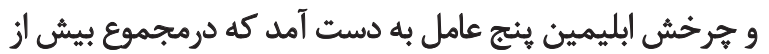

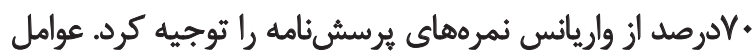

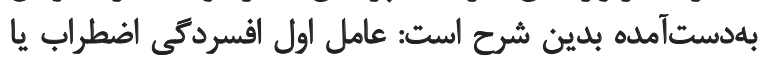

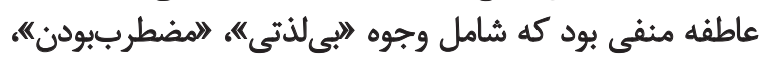

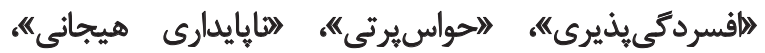

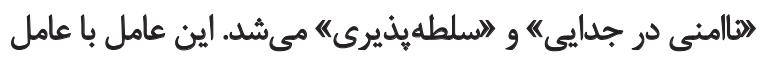

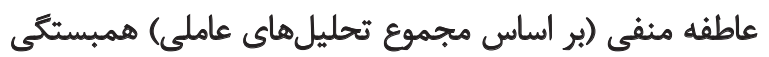
• I AVV

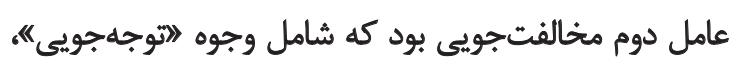

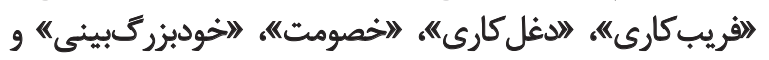


جدول r. بارهاى عاملى گويهها (وجوه)، مقدار عدد بحرانى (Eigenvalue) و درصد تبيين واريانس در ه عامل استخراجشده و جرخشيافته با روش direct oblimin

\begin{tabular}{|c|c|c|c|c|c|}
\hline روانيريشي ئجمئي & عايدل شهارم: عائاري & عاهل سوميكّى: & مخالفت مجوييى & 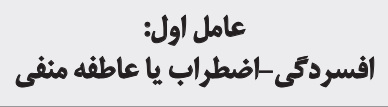 & سطع \\
\hline$-+1+\Delta r$ & $-* / 119$ & . /FAD & $-+/ 1 r$ & .191. & بـ لدثى \\
\hline - &.$/ 199$ & $.1+\pi$ & $-+1 \cdot M$ &.$M 19$ & مضطرب بودن \\
\hline.$/ \cdot m$ &.$/ 10 A$ & זוM & . IFAE & $\cdot 14 \cdot 9$ & ثوجلجويى \\
\hline$-*|\cdot r|$ & $-\cdot / \pi$ & - /RTA & $\cdot 10 \cdot F$ & $.1+\Delta \mid$ & سنكليلى \\
\hline $1 / 41$ & -+1198 & $1+\pi f$ & 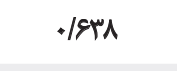 & .MIA & فريبكارى \\
\hline$-+/ 499$ & $-\cdot / 14$ & . MTA & $-+/ 1 r q$ & $\cdot N \cdot q$ & افسردكى يذيرى \\
\hline$-+/ T H F$ & $-+/ 118$ & /IFA & $1 / m$ & .1840 & حواسيرتى \\
\hline$=-M T T$ & -.1 .9 &.$/ 17 q$ & $.1 \cdot W$ &.$/ 1 \mathrm{RT}$ & غرابت \\
\hline$-\cdot /$ HAF & .1 .40 &.$- / 199$ &.$/$ IrD & .1879 & ثايايداري هيجائي \\
\hline.$- / 111$ &.$/ I V A$ & .1 .98 & - Are & $-\cdot / r \cdot V$ & خودبزركينيني \\
\hline.$- / N T Y$ & $.1 \cdot 1 r$ & . MrA & - Mtra &.$/ r n$ & خصومت \\
\hline - - /rat &.$- / P P Q$ & $-+1+\cdot V$ &.$/ 14 q$ & orti & تكانشكرى \\
\hline-.1 .18 & $.1 . .9$ & .184 & $.1+01$ & $-+1 *+\varphi$ & كريز از صميميت \\
\hline$-\cdot / 1 \cdot 1$ &.$- / F \Delta q$ & - /NA & /Mie & . rar & مسئوليتنايذيرى \\
\hline$-+1++4$ & $-+/ 1 F A$ & $1+\mu$ & ./Arه & $-+1+94$ & دغل كارى \\
\hline$-+/ v 8$ &.$- / .4$ & .1 .90 & 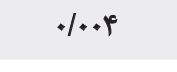 & .MIE & كرُتنظيمى ادراكى \\
\hline$-+/ 79)$ & ./FTQ & $* / T 11$ & $* \pi \cdot V$ &.$/ F \Delta r$ & درجازدمّى \\
\hline $.1 .8 V$ & $.1 \cdot p a$ & - /Ava & .11 .8 &.$- / 1 w$ & عاطفهيذيرى محدود \\
\hline$-\bullet / M T A$ &.$|N A|$ &.$M A P$ & - IFa & $\cdot 1 \cdot v 8$ & كمال طلبي ثامنعطف \\
\hline.$- / \mathrm{meV}$ & -.109 & $.1 \cdot 16$ &.$/ 19$ &.$- / 1 F t$ & خطريذيرى \\
\hline$-* 1 \cdot 19$ &.$-\left|+{ }^{\prime}\right|$ &.$- / M r m$ &.$/ 119$ & - Reqr & نالمنى در جداييى \\
\hline . TrEA & - Nea & $\bullet+\cdot V$ & . $+A Y$ & .MrV & سلطهيذيرى \\
\hline-+ TAY &.$/ .4 q$ & TMYS & . $M$ & $\cdot / M T$ & شكاكيت \\
\hline.$- / 978$ &.$/ 1 \cdot 1$ & -.1 .48 & .11 .8 & . NeE & باورها و تجارب نامعمول \\
\hline$-+/$ Iff & •MAY & IEAN & $-+/ N H$ & - Meq & انزوا \\
\hline VITV & $1 / \Delta 9 \Delta$ & $r / . .8$ & T/MTA & 1./AMr & مقدار Eigenvalue \\
\hline$P / \Delta \Delta$ & s/ru & $N \cdot r$ & q/Ta & $r T / I r$ & درصد تبيين واريانس \\
\hline
\end{tabular}

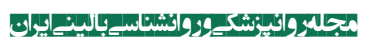
* * آستانه \&/ • براى بار قابل قبول عاملى در نظر كرفته شده است.

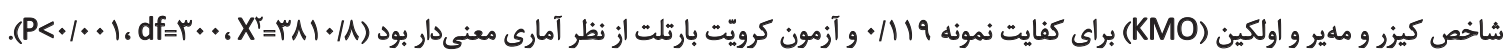




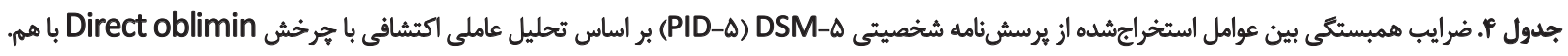

\begin{tabular}{|c|c|c|c|c|}
\hline روانيريشى كرايى & بايدارى رفتار & كسستئى & مخالفتجويى & \\
\hline$-\cdot / r \wedge q$ &.$/ .14$ & / RTr & $\cdot r \cdot r$ & افسردكى -ضطراب \\
\hline$-\cdot \mid$ PrI &.$- / 11 Y$ &.$/ N R$ & & هخالفتجويى \\
\hline.$- / M T V$ & -.1 .49 & & & كسيتكى \\
\hline .1 .90 & & & & بايدارى رفتار \\
\hline
\end{tabular}

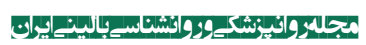

ماركون و همكاران، "آوجهجويى" بار عاملى مقبولى رادر زيركروه مخالفتجويى به دست آورده است.

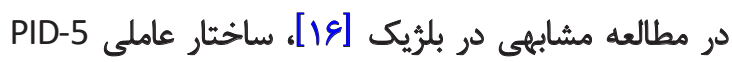

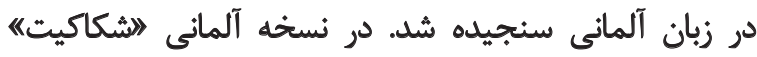

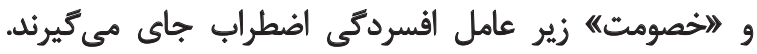

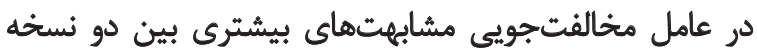

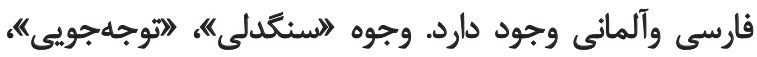

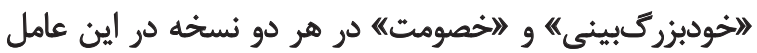

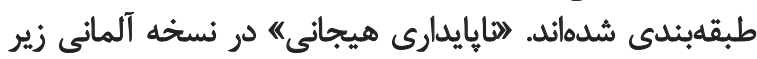

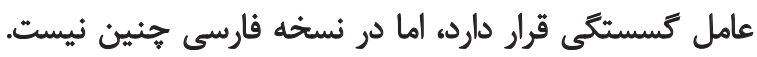

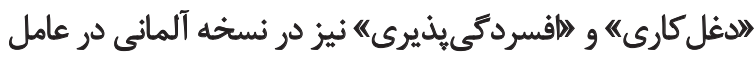

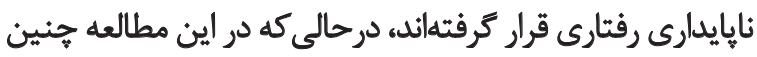

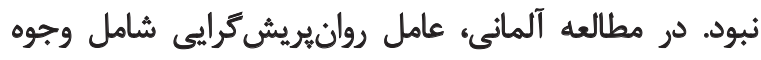

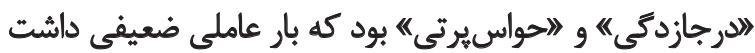

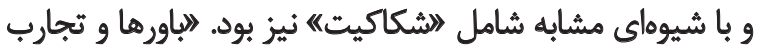

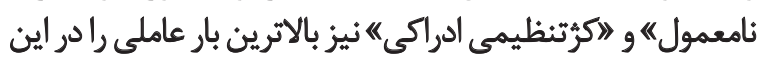

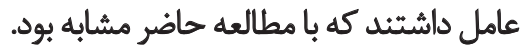

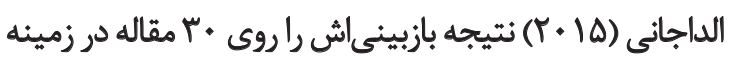

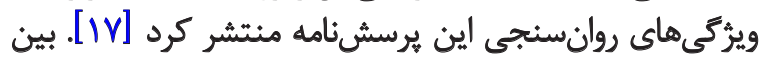

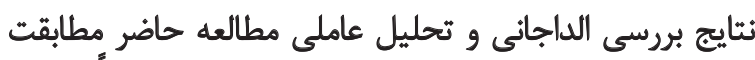

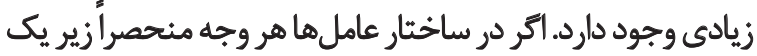

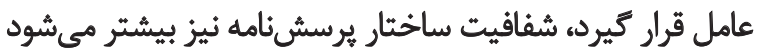

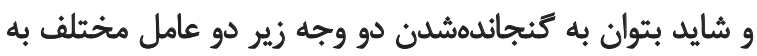

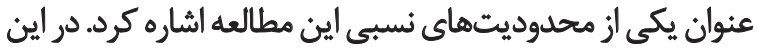

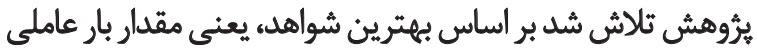

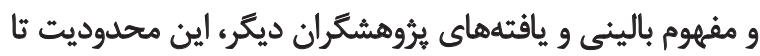

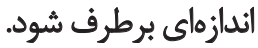

در كروههاى بررسى كراهد دو محدوديت عمده وجود داشت،

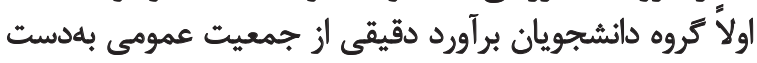

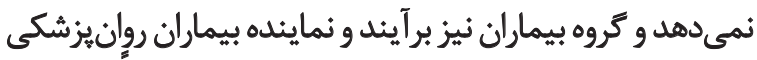

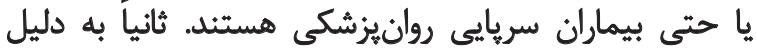

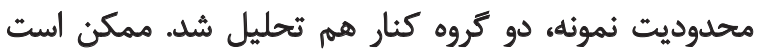

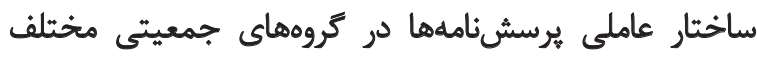

جهت معكوس) در مطالعه حاضر ازجمله اختلافات دو مطالعه

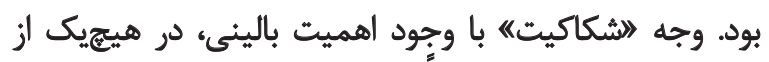

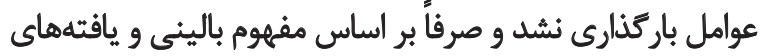

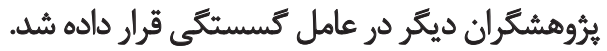

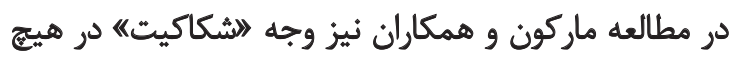

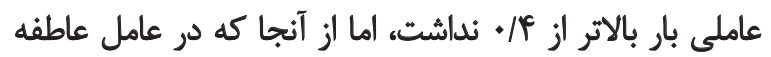

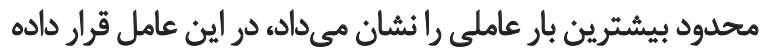

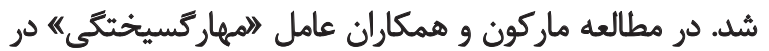

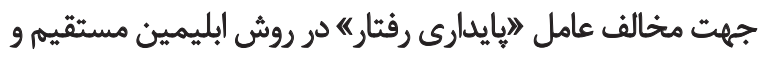

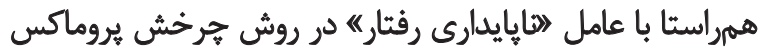

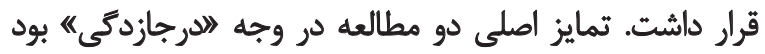

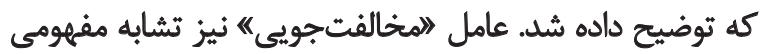

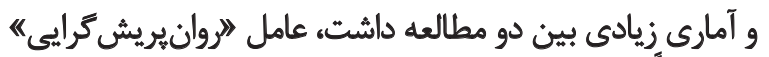

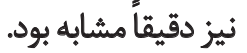

مطالعه ديكرى كه روى نسخه اسيانيايى اين برسش

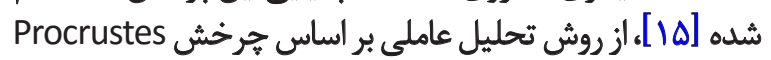

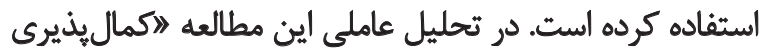

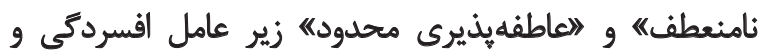

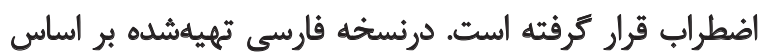

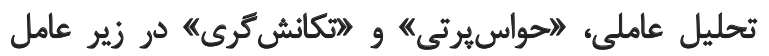

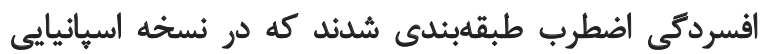

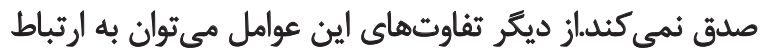

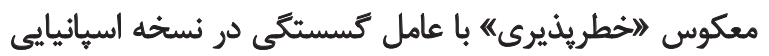

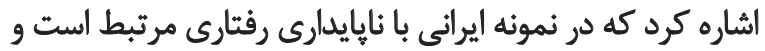

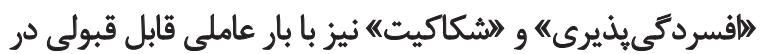

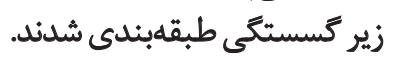

از ديكر تفاوتهاى نسخه اسيانيايعزبان با مطالعه حاضر، بار

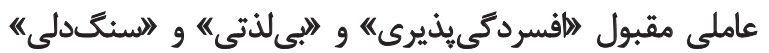

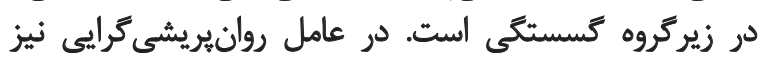

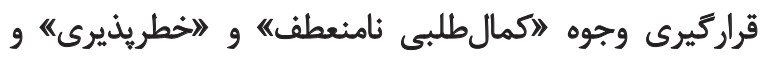

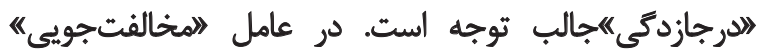

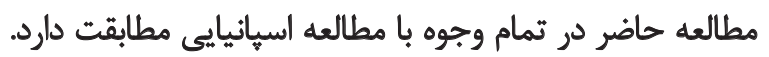

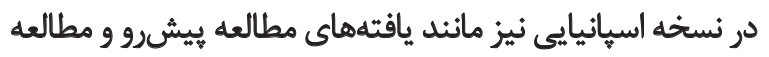




\section{References}

[1] Sadock BJ, Sadock VA. Kaplan and Sadock's comprehensive textbook of psychiatry. $9^{\text {th }}$ ed. Philadelphia: Williams \& Wilkins; 2009.

[2] American Psychological Association. Diagnostic and statistical manual of mental disorders. Washington D.C.: American Psychological Association; 2013

[3] American Psychological Association. Diagnostic and Statistical Manual of Mental Disorders. $4^{\text {th }}$ ed. Washington D.C.: American Psychological Association; 2000.

[4] Costa J, McCrea, Robert R. NEO-PI-R Professional Manual. Odessa, FL: Psychological Assessment Resources Inc; 1992.

[5] Goldberg L. The structure of phenotypic personality traits. American Psychologist. 1993; 48(1):26-34. doi: 10.1037//0003066x.48.1.26

[6] Cloninger C. The Temperament and Character Inventory (TCI): A guide to its development and use. Washington: Washington University Press; 1994

[7] Cattell RB, Cattell AK, Cattell H. 16PF Fifth Edition Questionnaire. Champaign, IL: Institute for Personality and Ability Testing; 1993.

[8] Russell MT, Karol D. The 16PF Fifth Edition administrator's manual. Champaign, IL: Institute for Personality and Ability Testing; 2002.

[9] Eysenck HJ, Eysenck SBG. Manual of the Eysenck Personality Questionnaire. London: Hodder and Stoughton; 1975.

[10] De Fruyt F, De Clercq B, De Bolle M, Wille B, Markon K, Krueger RF. General and maladaptive traits in a five-factor framework for DSM-5 in a university student sample. Assessment. 2013; 20(3):295-307. doi: 10.1177/1073191113475808

[11] Edmundson M, Lynam DR, Miller JD, Gore WL, Widiger TA. A five-factor measure of schizotypal personality traits. Assessment. 2011; 18(3):321-34. doi: 10.1177/1073191111408228

[12] Hopwood CJ, Thomas KM, Markon KE, Wright AGC, Krueger RF. DSM-5 personality traits and DSM-IV personality disorders. Journal of Abnormal Psychology. 2012; 121(2):424-32. doi: $10.1037 / \mathrm{a} 002665$

[13] Wright AGC, Thomas KM, Hopwood C], Markon KE, Pincus AL, Krueger RF. The hierarchical structure of DSM-5 pathological personality traits. Journal of Abnormal Psychology. 2012; 121(4):951-7. doi: 10.1037/a0027669

[14] Markon KE, Quilty LC, Bagby RM, Krueger RF. The development and psychometric properties of an informant-report form of the personality inventory for DSM-5 (PID-5). Assessment. 2013; 20(3):370-83. doi: 10.1177/1073191113486513

[15] Gutierrez F, Aluja A, Peri JM, Calvo N, Ferrer M, Bailles $\mathrm{E}$, et al. Psychometric properties of the Spanish PID-5 in a clinical and a community sample. Assessment. 2015. doi: $10.1177 / 1073191115606518$

[16] Bastiaens T, Claes L, Smits D, De Clercq B, De Fruyt F, Rossi G, et al. The construct validity of the Dutch Personality Inventory for DSM-5 personality disorders (PID-5) in a clinical sample. Assessment. 2016; 23(1):42-51. doi: 10.1177/1073191115575069

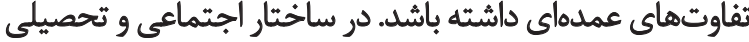
جامعه زمينههاى اجتماعى و اقتصادى و فرهنكى مختلفى وجئي دئي دارد كه ممكن است در استنباط افراد از مفاهيم و سؤال ها مؤثر

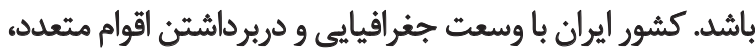

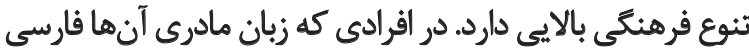

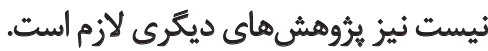

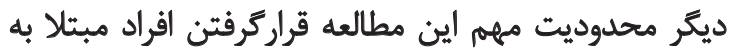

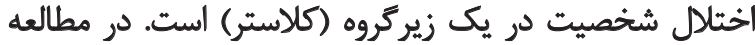

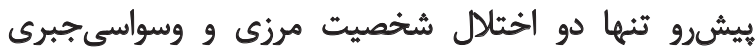

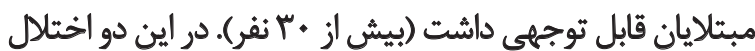

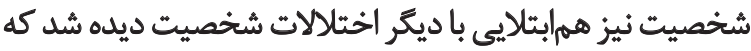

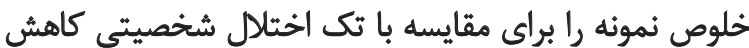

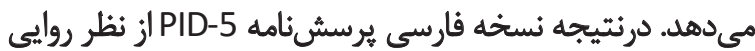

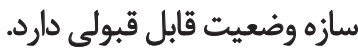
نتيجليكيرى 5نتايج مطالعه حاضر نشان مي دهد نسخه فارسى يرسشناميه

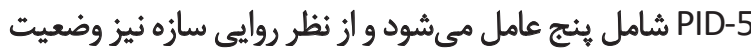

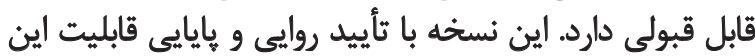

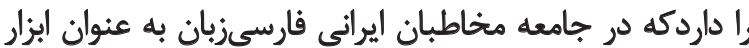
تحليل اختلالات شخصيتى، كاربرى بالينى داشته بارئه باشيد.

$$
\text { سياسكزازى }
$$

بدينوسيله از تمام دانشجويان و بيمارانى كه در اين مطالعه

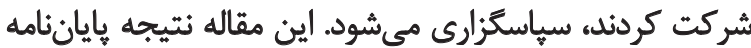

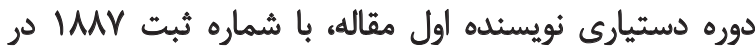
دانشعاه علوم بزشكى ايران است.

[بنا به اظهار نويسنده مسئول مقاله، حمايت مالى از برؤوهش و تعارض منافع وجود نداشته است.] 
[17] Al-Dajani N, GralnickTM, Bagby RM. A psychometric review of the personality inventory for DSM-5 (PID-5): Current status and future directions. Journal of Personality Assessment. 2016;98(1):62-81. doi: 10.1080/00223891.2015.1107572

[18] Norman GR, Streiner DL. Biostatistics: The bare essentials. Hamilton, Ontario: B. C. Decker Publications; 2000.

[19] Russell WD. In search of underlying dimensions: the use (and abuse) of factor analysis in personality and social psychology bulletin. Personality \& Social Psychology Bulletin. 2002; 28(12):16291646. doi: $10.1177 / 014616702237645$

[20] Watson D, Stasik SM, Ro E, Clark LA. Integrating normal and pathological personality: Relating the DSM-5 trait-dimensional model to general traits of personality. Assessment. 2013; 20(3):31226. doi: $10.1177 / 1073191113485810$

[21] Kamalzadeh L, Nayeri V, Soraya S, Shariat SV, Alavi K. [Testretest reliability and internal consistency of the Persian Version of Personality Inventory for DSM-5 (PID-5) in medical students and psychiatric patients (Persian)]. Journal of Isfahan Medical School. 34(393):901-907.

[22] Nayeri V, Soraya S, Kamalzadeh L, Bayat E, Shariat SV, Alavi K. [The translation and pschometric assessment of personality inventory for DSM-5 (Persian)]. Journal of Qom University of Medical Sciences. 2016; (In press). 